\title{
MODELO CALGARY DEAVALIAÇÃO DA FAMÍLIA: EXPERIÊNCIA EM UM PROJETO DE EXTENSÃO
}

Hellen Pollyanna Mantelo Cecilio', Katiucy Sturião dos Santos², Sonia Silva Marcon ${ }^{3}$

${ }^{1}$ Enfermeira. Mestre em Enfermagem. Universidade Estadual de Maringá. Maringá-PR-Brasil.

${ }^{2}$ Enfermeira. Universidade Estadual de Maringá. Maringá-PR-Brasil.

${ }^{4}$ Enfermeira. Doutora em Filosofia da Enfermagem. Universidade Estadual de Maringá. Maringá-PR-Brasil.

RESUMO: O objetivo do estudo foi avaliar a estrutura, a funcionalidade e o desenvolvimento da família, a partir do aparecimento da condição crônica. Estudo qualitativo, desenvolvido junto a duas famílias, que foram acompanhadas por um projeto de extensão. Utilizou-se o Modelo Calgary de Avaliação da Família, que propõe a utilização de três categorias de análise: estrutural, desenvolvimental e funcional, além do genograma e ecomapa. Uma família é nuclear e a outra é composta por apenas um indivíduo. A aplicação do modelo permitiu identificar as diferenças entre o apoio familiar na doença crônica e o enfrentamento do indivíduo sem a família. Com o envelhecimento surgem desafios a serem vivenciados e, para o idoso que vive só, tais enfrentamentos se agravam, pelo fato de estar privado de qualquer companhia.

DESCRITORES: Família; Doença crônica; Enfermagem.

\section{CALGARY MODEL OF FAMILY ASSESSMENT: EXPERIENCE IN A COMMUNITY SERVICE PROJECT}

\begin{abstract}
The study objective was to assess the family structure, functioning and development based on the emergence of a chronic condition. Qualitative study, developed in two families that were monitored through a community service project. The Calgary Model of Family Assessment was applied, which proposes the use of three analysis categories: structural, developmental and functional, besides the genogram and ecomap. One family is nuclear and the other consists of a single individual. Through the application of the model, the differences in family support for the chronic condition and the coping of the individual without family could be identified. Aging poses challenges that need to be experienced and, for elderly people living along, these confrontations are aggravated by the fact that they are deprived of any company.
\end{abstract}

DESCRIPTORS: Family; Chronic disease; Nursing.

\section{MODELO CALGARY DE EVALUACIÓN DE LA FAMILIA: EXPERIENCIA EN UN PROYECTO DE EXTENSIÓN}

RESUMEN: El objetivo del estudio fue evaluar la estructura, la funcionalidad y el desarrollo de la familia, considerando el aparecimiento de la condición crónica. Estudio cualitativo, desarrollado con dos familias que fueron acompañadas por un proyecto de extensión. Se utilizó el Modelo Calgary de Evaluación de la Familia, que propone la utilización de tres categorías de análisis: estructural, de desarrollo y funcional, además de genograma y ecomapa. Una familia es nuclear y la otra es compuesta por solo un individuo. La aplicación del modelo posibilitó identificar las diferencias entre el apoyo familiar en la enfermedad crónica y el afrontamiento del individuo sin la familia. Con el envejecimiento vienen desafíos que serán experenciados $y$, para el anciano que vive solo, tales afrontamientos se agravan, por el hecho de estar privado de cualquier compañía.

DESCRIPTORES: Familia; Enfermedad crónica; Enfermería. 


\section{INTRODUÇÃO}

A família é constituída por um grupo de pessoas que se relacionam entre si e são unidas por laços de consanguinidade, interesse ou apenas afetivos e que convivem em um contexto histórico, cultural, físico e político ${ }^{(1)}$, permitindo uma identidade própria. Permeada por crenças, valores e costumes que foram construídos e transmitidos por gerações, a família forma a personalidade dos seus membros e guia os cuidados e as ações para a promoção e recuperação da saúde e a prevenção de $\operatorname{agravos}^{(2)}$. Neste sentido, cabe à enfermagem o papel de intervir, com a finalidade de promover a autonomia de cuidados, considerando a individualidade, as crenças e valores, visando capacitá-los para sua independência ${ }^{(1)}$.

Uma das causas que constitui maior demanda para o cuidado familiar no processo saúdedoença são as doenças crônicas, que possuem fatores de risco em comum e demandam uma assistência e atenção continuada, estando muitas vezes relacionadas ao envelhecimento ${ }^{(2)}$. Por este motivo, a condição crônica, quando afeta um membro da família, costuma tornar-se motivo de sobrecarga, uma vez que necessita desde cuidados diários até as hospitalizações recorrentes e prolongadas, além de ser um agente estressor para o próprio doente e para o relacionamento social do sistema familiar. Sendo assim, percebe-se que as alterações emocionais e sociais decorrentes desse processo em uma família, requerem cuidados constantes e adaptações à nova situação.

Considerando o impacto causado pela doença, optamos por utilizar o Modelo Calgary de Avaliação na Família (MCAF) que possibilita uma visão ampliada do sistema familiar, o que inclui suas relações internas e externas, fortalezas e fragilidades ${ }^{(2-3)}$. A utilização deste modelo permite ao enfermeiro conhecer a família em seu contexto e identificar suas necessidades, bem como alternativas de cuidado específicas a sua condição. Diante disto, surgiu o questionamento: qual a influência da família nos cuidados e na adesão ao tratamento a partir do aparecimento de uma condição crônica? Para respondê-lo, definimos como objetivo do estudo avaliar, por meio do MCAF, a estrutura, a funcionalidade e o desenvolvimento da família, a partir do aparecimento da condição crônica.

\section{MÉTODO}

Estudo qualitativo desenvolvido junto a duas famílias assistidas há aproximadamente um ano, pelo projeto de extensão "Assistência e Apoio a Família de Doentes Crônicos no Domicílio", vinculado ao Núcleo de Estudo, Pesquisa, Assistência e Apoio a Família do Departamento de Enfermagem da Universidade Estadual de Maringá-PR-Brasil. O projeto de extensão assiste famílias de pessoas com doenças crônicas que estiveram internadas no Hospital Universitário e aceitaram receber visitas dos acadêmicos. A seleção das famílias incluídas neste estudo foi baseada na conveniência e na percepção dos acadêmicos sobre o interesse da família em participar.

Como referencial metodológico foi utilizado o MCAF e suas três categorias principais. A avaliação estrutural diz respeito à composição da família, os vínculos afetivos entre seus membros em comparação com os indivíduos de fora e o seu contexto, constituída por três aspectos: estrutura interna, estrutura externa e contexto ${ }^{(3)}$. Para delinear tais aspectos são utilizados o genograma e o ecomapa; o primeiro é um diagrama representativo do grupo familiar, ou seja, é uma árvore familiar que representa a estrutura interna. $\mathrm{O}$ genograma tem como objetivo principal auxiliar na avaliação, planejamento e intervenção familiar e permite ainda, observar de forma clara quais membros constituem a família, além da identificação das principais enfermidades, facilitando o plano terapêutico ${ }^{(1)}$. O ecomapa é um complemento do genograma e consiste em uma representação gráfica dos contatos dos membros da família com a comunidade, permitindo avaliar as redes e apoios sociais disponíveis e sua utilização pela família. Este é um instrumento dinâmico, pois mostra a ausência ou presença de recursos sociais, culturais e econômicos de um determinado momento do ciclo vital da família ${ }^{(1)}$.

A avaliação funcional diz respeito aos detalhes sobre como os indivíduos se comportam uns com os outros, baseando-se no funcionamento instrumental referente às atividades da vida cotidiana e no funcionamento expressivo, que se refere aos papéis familiares, a comunicação e a resolução de problemas $^{(3)}$. Por fim, a avaliação desenvolvimental enfatiza a trajetória exclusiva construída por uma família e é modelada por eventos previsíveis e imprevisíveis, tais como doenças, catástrofes e tendências sociais ${ }^{(3)}$, que implicam em mudanças 
no funcionamento da família, na sua estrutura e nos seus processos de interação( ${ }^{(1)}$.

A coleta de dados foi realizada entre agosto e novembro de 2012, por meio de seis visitas domiciliares para as famílias, conforme o plano de acompanhamento previsto no projeto. A construção do genograma e do ecomapa foi feita com a participação ativa da família, com liberdade para discussões e considerações sobre os diagramas, além das orientações específicas para cada situação vivenciada. O desenvolvimento do estudo ocorreu em conformidade com os preceitos éticos e o projeto foi aprovado pelo Comitê Permanente de Ética em Pesquisa com Seres Humanos da Universidade Estadual de Maringá (Parecer 084/2006).

\section{RESULTADOS}

A família um era composta por Adão, Eva e Abel, conforme Figura 1. Adão tinha 76 anos, analfabeto e aposentado por invalidez há 14 anos, sofria de hipertensão arterial sistêmica e relatou seis acidentes vasculares cerebrais, o primeiro foi há mais de 16 anos e deixou como sequela a hemiparesia esquerda, impossibilitando a deambulação. Os cinco sequentes foram com menor intensidade e não deixaram sequelas visíveis. Adão relatou que bebia e fumava muito antes do primeiro acidente vascular cerebral, trabalhava como pedreiro, mas condição de saúde está em cadeira de rodas, assistindo televisão ou dormindo. Ele depende de auxílio dos familiares para todas as atividades. Na época em que sofreu o referido acidente vascular, ele foi orientado a utilizar medicação e fazer fisioterapia, no entanto ele optou por não aderir ao tratamento e ainda resiste a tomar medicamentos e realizar os cuidados necessários com a saúde. Adão mostrou não gosta de falar sobre sua saúde e ficou agressivo com a esposa quando ela comentou sobre o assunto.

Eva, sua esposa, tinha 73 anos, aposentada, estudou menos de quatro anos e trabalhava no campo. Eva também tinha hipertensão arterial, artrose em ambos os joelhos agravada pelo excesso de peso, passou por um procedimento cirúrgico no início de 2012 para correção de cistocele e em agosto deste mesmo ano, passou por outro procedimento cirúrgico para correção de uma hérnia umbilical. No período de coleta de dados, ela ainda se recuperava da cirurgia e sua filha, Maria, estava acompanhando-a e ajudando a cuidar de Adão. Em vários momentos Eva referiu estar sobrecarregada e cansada, pois passava boa parte do dia dedicando-se ao marido, ao filho e às atividades domésticas. Relatou que sofria com a desobediência de Adão e, também, quando o filho estava sob efeito do álcool. Sua condição de saúde também necessitava de cuidados diários com medicamentos corretos, alimentação e muitas vezes o estresse prejudicava sua situação.

Abel tinha 49 anos, solteiro, morava com os pais e estava desempregado; tinha deficiência auditiva e apresentava sinais de transtorno mental, mas a família não sabia informar ao certo o diagnóstico, porém relataram que os sinais estavam presentes desde o nascimento. Segundo informou a mãe, fazia uso de bebida alcoólica com frequência, ficando alterado e agressivo sob o efeito do álcool. Abel era o principal ajudante de Eva para os cuidados com a casa e com Adão, ele auxiliava o pai no banho, na utilização do sanitário e na locomoção, ao passo que Eva ficava encarregada de cuidar da alimentação. Abel também ajudava Eva na limpeza da casa e no serviço pesado como lavar roupa e calçadas.

Os demais filhos do casal eram casados e raramente visitavam os pais, deixando para Abel a responsabilidade em acompanhar e cuidar dos pais. Aparentemente, ele desempenhava bem o papel de cuidador, no entanto, tornava-se agressivo quando discordavam dele e quando bebia. A maior dificuldade da família era a renda, pois sobreviviam apenas da aposentadoria de Adão e Eva, que além das despesas de casa, precisavam comprar medicamentos não oferecidos pela Unidade Básica de Saúde. Referem também, que os vizinhos e um grupo de uma igreja que frequentavam faziam doações de alimentos e roupas esporadicamente.

Eva tinha um bom vínculo com a equipe de saúde da família, representada pela enfermeira e relatou ser sempre bem atendida na unidade básica de saúde, entretanto, referiu que a médica da equipe não mantém muito contato. Todavia, Adão por ficar restrito em casa, recebeu visita da enfermeira uma vez ao mês e da agente comunitário de saúde toda semana, ambas com bom vínculo com a família, de acordo com a Figura 2.

A família dois, representada na Figura 3, era composta apenas por Pedro, 70 anos, solteiro, aposentado, sem filhos e sem parentes de primeiro grau próximos; estudou apenas três anos, pois precisava trabalhar para contribuir com a renda familiar. Pedro tinha hipertensão arterial, diabetes mellitus, labirintite e reumatismo. Ficava em casa a maior parte do tempo e não costumava conversar com os vizinhos. Por morar sozinho, ele mesmo 
realizava as atividades domésticas, como lavar, passar e cozinhar. Em uma das visitas domiciliares realizadas e contato com a equipe da Estratégia Saúde da Família certificou-se que comparece pouco a unidade básica de saúde e quando vai se lamenta muito pela demora no atendimento. Também, não permitia a visita da agente comunitário de saúde em sua casa. No entanto, segundo ele, a

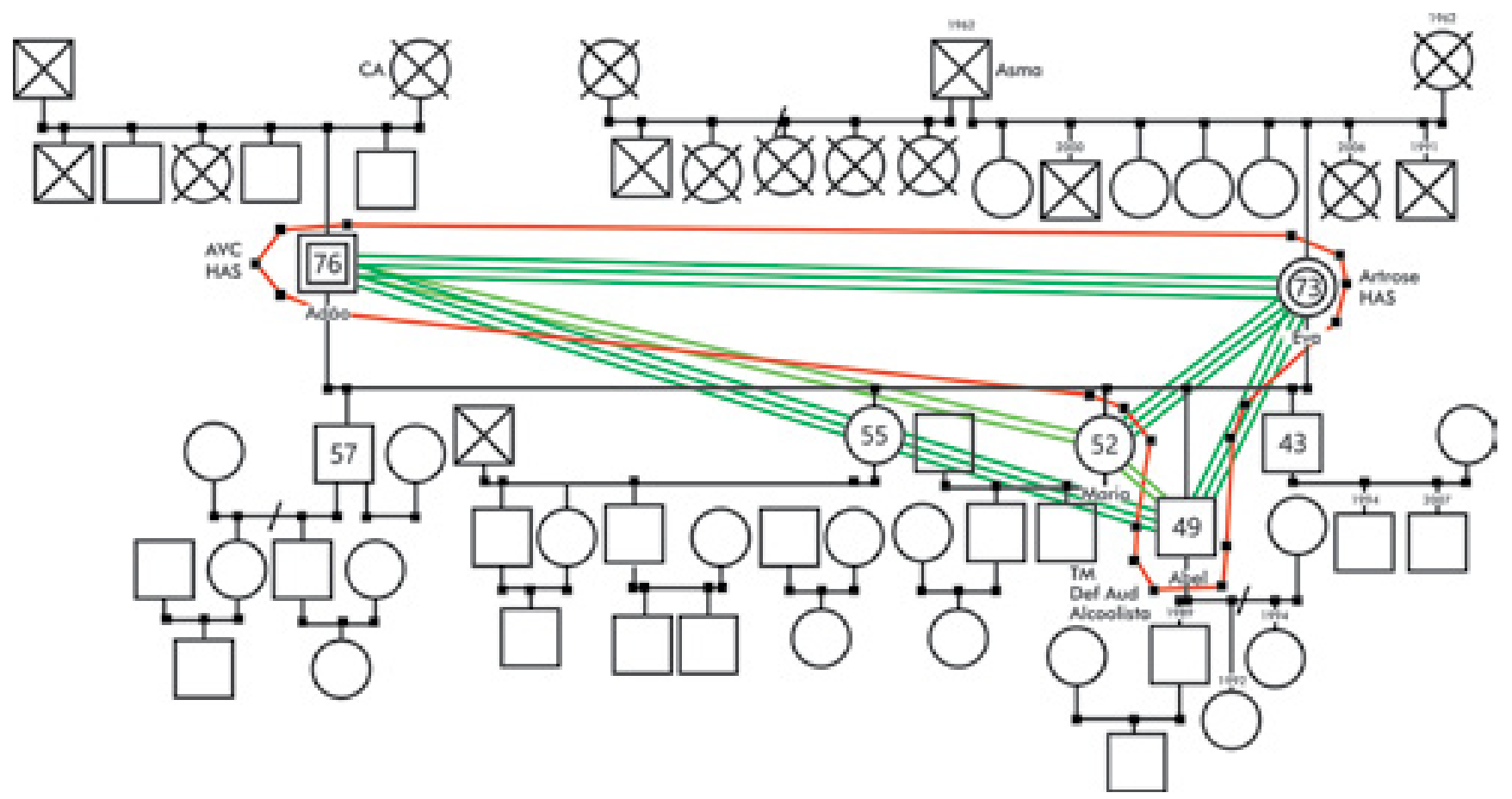

\begin{tabular}{|c|c|c|c|c|c|}
\hline \multicolumn{2}{|r|}{ LEGENDA } & (2) [D] & Pessoa indice & AVC & Acidente Vascular Cerebral \\
\hline ⿷ & Homem & 뭉 & Casamento & HAS & Hipertensalo Arterial Sistêmica \\
\hline 0 & Muther & 마 $\beta$ & Separaço & Def Aud & Deficiencia Auditiva \\
\hline$\triangle \infty$ & Obito &  & Estreito & $\mathbf{T M}$ & Transtomo Mental \\
\hline Ex & Moram juntos & $=$ & Próximo & CA & Cancer \\
\hline
\end{tabular}

Figura 1 - Genograma da Família 1. Maringá-PR-Brasil, 2012
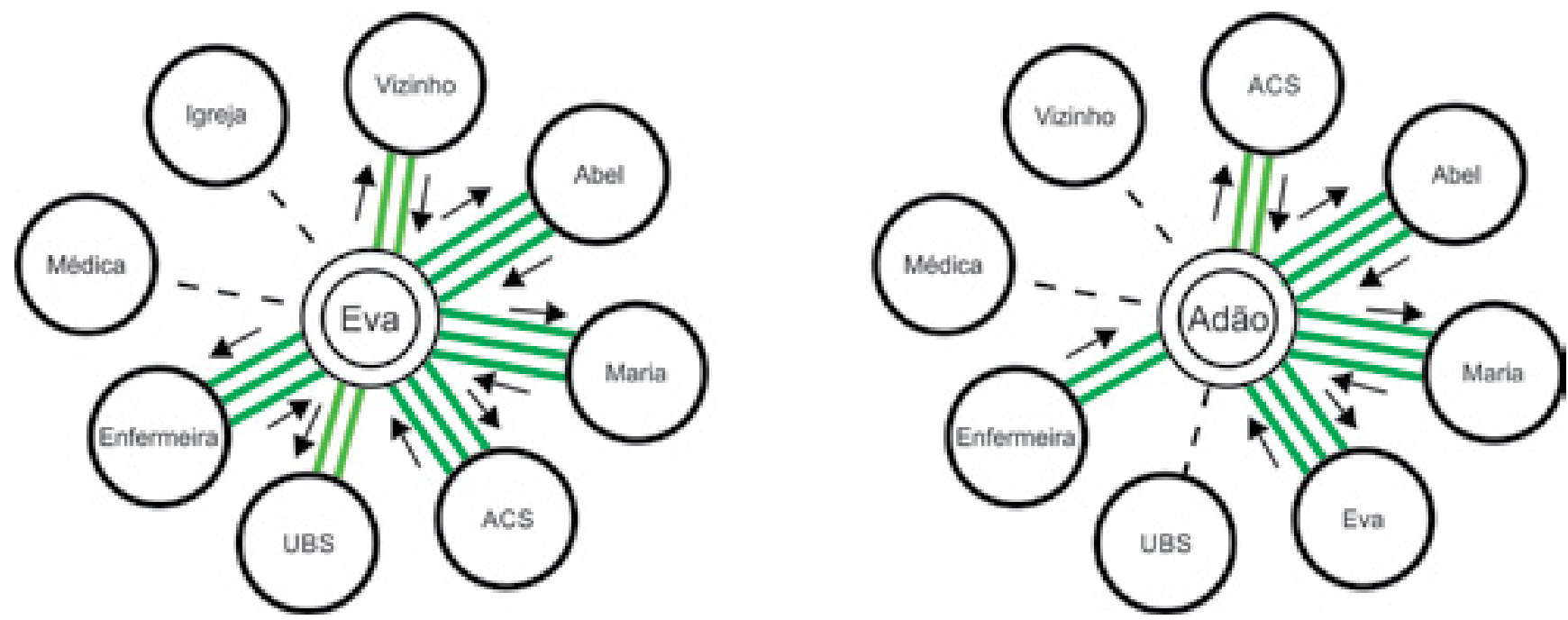

\begin{tabular}{|l|l|l|l|}
\hline \multicolumn{2}{|c|}{ LEGENDA } & --- & Vinculo distante \\
\hline \hline & Vinculo moderado & $\longrightarrow$ & Fluxo de energia \\
\hline \hline & Vinculo superficial & UBS & Unidade Básica de Saúde \\
\hline
\end{tabular}

Figura 2 - Ecomapa da Família 1. Maringá-PR-Brasil, 2012 
enfermeira e o médico nunca foram a sua casa e era difícil conseguir atendimento.

Pedro ignorou todas as tentativas de conversar sobre sua família, tentando sempre mudar de assunto, assim como também não gostava de falar sobre sua saúde. A forma encontrada para conhecer sua história foi por meio do MCAF, pois ele se interessou pela construção do genograma e do ecomapa e contou um pouco sobre sua família. Pedro tinha seis irmãos vivos e todos residiam em outras cidades, sendo esse o motivo pelo qual os encontra apenas esporadicamente, porém mantinha contato por telefone.

Joaquim, seu irmão caçula, era portador de transtorno mental e necessitava de cuidados e, por esse motivo o via mais vezes. No entanto, essa relação era um tanto conflituosa, pois Joaquim não aceitava sua situação e era resistente a qualquer ajuda dos irmãos. O único familiar com quem Pedro convivia frequentemente e mantinha relação harmoniosa era seu sobrinho Timóteo (Figura 4).

Em relação aos cuidados de saúde, Pedro não fazia uso correto da medicação, não seguia a dieta recomendada para o diabetes e não se preocupava em cuidar da higiene corporal e nem da limpeza e organização da casa. Também, por viver sozinho, ele era responsável por sua alimentação e não realizava as refeições corretamente, segundo ele, na maioria das vezes, substituía o almoço e o jantar por frutas, como laranja e banana. Em grande parte das visitas realizadas, ele se apresentava com visível falta de higiene bucal e com roupas sujas, e, em algumas vezes, era possível sugerir a falta de banho por alguns dias.

O quintal da sua casa servia como depósito de entulhos e de materiais de construção, acumulando água quando chovia. Durante as visitas domiciliares Pedro sempre recebeu as pesquisadoras no quintal e no máximo na varanda; a essa distância foi possível observar que o interior da casa aparenta pouca limpeza, a cozinha e a sala apresentam entulhos e materiais que, possivelmente, ele recolhe na rua, porém negou essa atividade.

Pedro sobrevivia de sua aposentadoria e sempre que possível realizava alguns serviços extras de pedreiro e carpinteiro. Ele afirmou que os serviços extras eram necessários, porque a aposentadoria não era suficiente para comprar alimentos e muito menos para comprar alguns medicamentos não disponibilizados pela unidade básica de saúde. Relatou ainda, que algumas vezes, precisou pedir ajuda ao sobrinho para pagar as despesas e que algumas vezes para comprar alimentos. No entanto, na ocasião das visitas não foi possível perceber a falta de alimentos referida por ele, pois sempre havia, inclusive, frutas em grande quantidade.



\begin{tabular}{|c|c|c|c|c|c|}
\hline \multicolumn{2}{|r|}{ LEGENDA } & (2) 0 & Pessoa indice & $\sim \sim$ & Conflito \\
\hline$\square$ & Homem & ㅁㅇ & Casamento & HAS & Hipertensão Arterial Sistêmica \\
\hline O & Mulher & 묘 & Separação & DM & Diabetes Mellitus \\
\hline$\otimes \otimes$ & Óbito & $\equiv$ & Estreito & AVC & Acidente Vascular Cerebral \\
\hline
\end{tabular}

Figura 3 - Genograma da Família 2. Maringá-PR-Brasil, 2012 


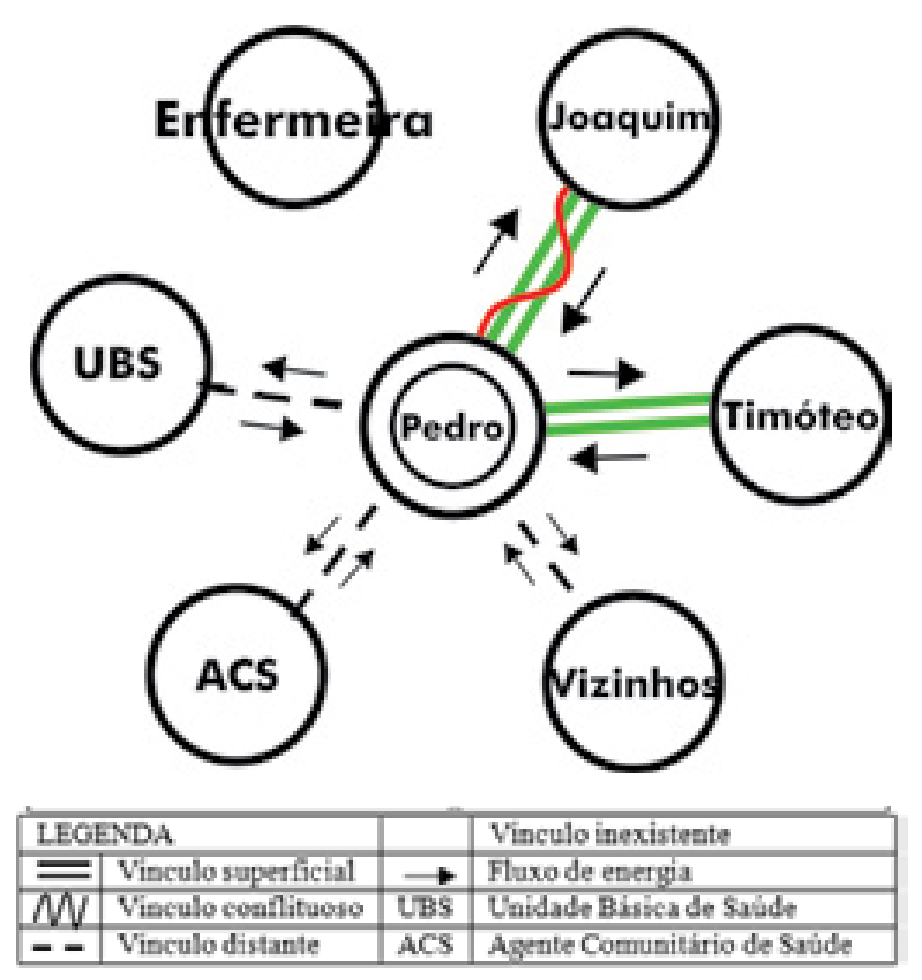

Figura 4 - Ecomapa da Família 2. Maringá-PR-Brasil, 2012

\section{DISCUSSÃO}

As duas famílias eram de tipologias diferentes, a primeira era a típica família nuclear, representada pela mãe, pai e filho solteiro, e a segunda composta apenas por um indivíduo. Juntamente com o envelhecimento surgem desafios a serem vivenciados pelo indivíduo, e para o idoso que vive só esses enfrentamentos se agravam, pelo fato de estar privado de qualquer companhia que possa auxiliá-lo na realização de suas atividades. Tais desafios são relacionados ao autocuidado, as enfermidades que precisam enfrentar, a insuficiência econômica, entre outras ${ }^{(4)}$.

Sendo assim, quando o indivíduo idoso mora sozinho, principalmente quando existe ausência de contato familiar, a tendência é que o mesmo vivencie maiores dificuldades para recuperação do seu estado de saúde. De fato, idosos que residem com outras pessoas, sejam elas integrantes da família ou não, parecem estar mais amparados em relação à atenção dada aos seus problemas de saúde ${ }^{(4)}$. A solidão interfere na qualidade de vida da pessoa, pois a privação do convívio e o isolamento social causam sofrimento, tornando-a triste e limitada ${ }^{(2,5)}$. Esse fato foi observado na segunda família, visto que Pedro não desfrutava de companhia em seu diaa-dia.
Pedro não contava com o apoio da família de origem pelo fato de residirem distantes, tampouco com sua própria família, pois não a constituiu. Isto dificulta o enfrentamento da condição crônica e a realização de atividades da vida diária, como por exemplo, o preparo de uma refeição adequada, a administração correta dos medicamentos de uso contínuo, o acompanhamento das condições de saúde por meio de consultas regulares; aspectos estes que prejudicam o controle da doença, a manutenção da saúde, a qualidade de vida e a prevenção de agravos ${ }^{(2,5)}$.

O apoio da família ao doente crônico, portanto, é imprescindível, pois tornar-se doente inclui a vivência de uma série de mudanças pessoais e familiares, salientando que dependendo da gravidade da doença é necessário que sejam feitas alterações na forma de viver da família. Ao mesmo tempo, as mudanças, muitas vezes, são vistas como desnecessárias, o que ocorre especialmente nos casos em que as doenças não apresentam sinais e sintomas evidentes ${ }^{(2)}$.

$\mathrm{O}$ agravamento do quadro, somado às alterações biológicas, psicológicas e fisiológicas próprias do envelhecimento geralmente levam a limitações motoras, sensitivas e sensoriais, alterando a dinâmica da vida dos idosos e restringindo as atividades diárias ${ }^{(6)}$ surgindo, assim, algum tipo de dependência, o que requer a 
reestruturação dos papéis de todos os membros da família ${ }^{(4)}$, visto que o idoso perde sua autonomia para outrem ${ }^{(6)}$. Neste momento de dependência, o carinho e o respeito da família contribuem decisivamente para um final de vida feliz ${ }^{(5)}$.

O cuidador, nestes casos, comumente é escolhido pelo grau de afinidade com o doente, por não trabalhar fora, e muitas vezes, simplesmente por ser mulher ${ }^{(7)}$. Este fato reflete o padrão cultural brasileiro, em que o papel de cuidador principal, ainda é visto como uma função feminina. No entanto, como no caso da família 1, o filho também desempenhava papel de cuidador, auxiliando o pai nas atividades básicas e instrumentais da vida diária ${ }^{(8)}$. É válido ressaltar que, quase sempre, os cuidadores sentem-se sobrecarregados com suas funções, principalmente se o cuidador residir com o idoso. Isto foi expresso na família 1, pois apesar de o cuidado ser dividido entre mãe e filho, ambos estavam expostos constantemente as demandas de cuidado, além de terem que realizar outras atividades ${ }^{(7)}$. Sendo assim, uma forma de minimizar as dificuldades encontradas na demanda do cuidado prestado ao indivíduo dependente, é o acompanhamento, orientação e suporte oferecido pelos profissionais de saúde ${ }^{(7)}$.

É comum que os cuidadores apresentem exclusão social, isolamento afetivo, depressão e distúrbios do sono $^{(6)}$, visto que é o indivíduo que absorve níveis diferentes de ansiedade no processo de cuidado $^{(7)}$. Vale ressaltar ainda, que é comum o cuidador do idoso ser outro idoso, já frágil pelo envelhecimento e em vias de adoecer ${ }^{(9)}$, com desgaste físico, diminuição da força e da agilidade, além de outras doenças(10), como na família 1.

Outro aspecto a ser lembrado é a transformação da relação entre paciente e cuidador, antes de reciprocidade e que passa a ser de dependência, de modo que o cuidador tem restrições em sua própria vida ${ }^{(10)}$. Assim, faz-se necessário que a equipe de enfermagem desempenhe seu papel de apoiar psicologicamente e promover a saúde do familiar cuidador, uma vez que o bem-estar físico e mental deste interfere diretamente no cuidado a ser prestado(10-11).

É importante ainda, conhecer a escolaridade dos cuidadores, pois são eles que recebem as informações e orientações da equipe de saúde, e a educação para a saúde está ligada a capacidade de aprendizagem das pessoas ${ }^{(9)}$. Compreendese que o conhecimento do cuidador, quando limitado devido a baixa escolaridade, interfere nos cuidados ao idoso, com queda na qualidade da atenção prestada ${ }^{(8)}$, pois é ele que irá vivenciar o cotidiano da doença e suas implicações, assim como é ele quem vai buscar maneiras de lidar com a essa realidade ${ }^{(12)}$.

Perante isto, a baixa condição socioeconômica das famílias em estudo, por si só já constitui um grande empecilho para o cuidado. Em uma família, dificulta o próprio paciente em manter uma boa qualidade de vida e na outra, dificulta que o cuidador ofereça os cuidados adequados, pois são necessários recursos financeiros que possibilitem a aquisição e a compra de alimentos, medicamentos, além de transporte e outras necessidades que surgem com a dependência ${ }^{(7)}$. Diante desse fato, é de responsabilidade do enfermeiro e da sua equipe conhecer a realidade, bem como as necessidades da família assistida, a fim de planejar intervenções que sejam condizentes com a real necessidade dos indivíduos e adequadas à sua condição financeira ${ }^{(4)}$.

Todavia, existem outros fatores que interferem no cuidado e na assistência de qualidade, entre eles, a aceitação do doente de sua situação e, principalmente, do tratamento, sendo medicamentoso ou não. Em ambos os casos, os pacientes eram relutantes quanto à adesão ao tratamento, o que pode ser explicado pela baixa escolaridade, dificuldade de entendimento e até mesmo pela falta de confiança e vínculo com familiares e profissionais de saúde.

A adesão ao tratamento é um processo conjunto entre paciente e profissional, de forma que aquele não apenas obedece, mas entende, concorda e segue as orientações, sinalizando uma aliança terapêutica entre equipe, paciente e família, na qual cada um tem suas responsabilidades no processo ${ }^{(13)}$. Neste sentido, vê-se a importância de reunir esforços para aperfeiçoar recursos e estratégias, com a participação de todos os envolvidos no processo, visto que a adesão à terapêutica seja ela medicamentosa ou não, é importante quando se trata de um indivíduo idoso ${ }^{(14)}$.

É comum a não-adesão ao tratamento ser percebida como uma frustração pelos profissionais de saúde ${ }^{(14)}$ e, mesmo se o paciente não aderir 
ao tratamento, ele necessita de cuidado, afeto e de orientação para o alcance dos seus objetivos. Frente a não-adesão é necessário orientar e explicar as consequências, tanto ao paciente quanto para a família, que devem entender a importância de acatar o regime terapêutico ${ }^{(13)}$. A enfermagem é imprescindível para atuar neste contexto, visando não só apenas influenciar o comportamento do paciente para mudanças, mas também para manutenção delas, sugerindo transformações leves e gradativas, as quais podem ser mais facilmente adotadas pelo paciente e família ${ }^{(14)}$. Além disso, existe a necessidade de treinar e supervisionar a execução das atividades do cuidador, de modo que ele preste um cuidado de qualidade, sem, contudo, prejudicar sua própria saúde ${ }^{(2)}$.

Ressalva-se que os significados das doenças crônicas não são exclusivos do indivíduo doente, mas propriedade de todos os membros da família e da sua rede social, pois são compartilhados entre si e influenciam direta ou indiretamente no curso da doença, auxiliando na redução ou aumento das dificuldades, ou nos impedimentos ou facilidades do tratamento ${ }^{(15)}$. Por este e outros fatores, compreende-se que a abordagem individual, em detrimento da abordagem familiar, pode conduzir uma avaliação e, consequentemente, uma intervenção limitadas, mostrando o despreparo dos serviços de saúde e dos profissionais envolvidos com a atenção ao idoso, configurando como um obstáculo que compromete a competência e a qualidade da assistência prestada ao idoso ${ }^{(16)}$.

Finalmente, salienta-se que todo ser humano necessita conviver com outras pessoas, para um bem-estar biopsicossocial, sendo que as relações sociais estimulam a mente e o pensamento, tendo efeitos benéficos sobre a saúde, contribuindo para a melhoria da qualidade de vida de toda a família $^{(5)}$. A enfermagem, enquanto ciência que cuida, deve sempre inserir a família no cuidado, com vistas a diminuir as sobrecargas individuais, evitando transformar o cuidador em alguém que futuramente possa necessitar de cuidados $^{(9)}$.

\section{CONSIDERAÇÕES FINAIS}

Diante dos desafios do envelhecimento juntamente com os agravos das doenças crônicas, os pacientes necessitam de auxílio para as diferentes atividades diárias, sendo possível verificar as disparidades e semelhanças entre as famílias. Ter um cuidador na família é um fator de menos estresse para o doente, pois o cuidado é humanizado e respeita seus costumes e crenças, no entanto é um fator de mais estresse para quem cuida que precisa abrir mão das suas necessidades em detrimento do doente. No entanto, além do apoio e acompanhamento da família, faz-se necessário que o doente crônico entenda sua condição e participe ativamente das decisões tomadas, aderindo ao tratamento e minimizando as chances de complicações.

\section{REFERÊNCIAS}

1. Figueiredo MHJS, Martins MMFS. Avaliação familiar: do Modelo Calgary de Avaliação da Família aos focos da prática de enfermagem. Cienc. cuid. Saúde. 2010;9(3):552-9.

2. Santos AL, Cecilio HPM, Teston EF, Marcon SS. Conhecendoafuncionalidadefamiliar sobaótica dodoente crônico. Texto Contexto Enferm. 2012;21(4):879-86.

3. Wright LM, Leahey M. Enfermeiras e famílias: um guia para avaliação e intervenção na família. $3^{a}$ ed. São Paulo: ROCA; 2002.

4. Ramos JLC, Menezes MR, Meira EC. Idosos que moram sozinhos: desafios e potencialidades do cotidiano. Rev. baiana enferm. [Internet] 2010;24(1/3):43-54 [acesso em 10 abr 2013]. Disponível: http://www.portalseer. ufba.br/index.php/enfermagem/article/view/5527/3979

5. Lopes RF, Lopes MTF, Camara VD. Entendendo a solidão do idoso. RBCEH. [Internet] 2009;6(3):373-81 [acesso em 10 abr 2013]. Disponível: http://www.upf. br/seer/index.php/rbceh/article/view/362/818

6. Costa JBE, Guimarães RM, Ananias SP. Análise do impacto de um programa de orientação/ educação na sobrecarga e qualidade de vida de cuidadores de idosos. Rev. Tecer. [Internet] 2008;1(0):37-47 [acesso em 10 abr 2013]. Disponível: http://pe.izabelahendrix. edu.br/ojs/index.php/tec/article/view/268/228

7. Uesugui HM, Fagundes DS, Pinho DLM. Perfil e grau de dependência de idosos e sobrecarga de seus cuidadores. Acta Paul. Enferm. [Internet] 2011;24(5):689-94 [acesso em 15 mai 2013]. Disponível: http://dx.doi.org/10.1590/S0103-21002011000500015

8. Santos AA, Pavarini SCI. Funcionalidade familiar de idosos com alterações cognitivas: a percepção do cuidador. Rev Esc Enferm USP. [Internet] 2012;46(5):1141-7 [acesso em 15 mai 2013]. Disponível: http://dx.doi.org/10.1590/S008062342012000500015 
9. Araújo JS, Silva SED, Santana ME, Conceição VM, Vasconcelos EV. O perfil representacional dos cuidadores de pacientes acometidos por acidente vascular cerebral. Gestão \& Saúde [Internet] 2012;3(3):852-64 [acesso em 10 mai 2013]. Disponível: http://gestaoesaude.unb.br/index.php/gestaoesaude/ article/view/183/pdf_1.

10. Oliveira WT, Antunes F, Inoue L, Reis LM, Araújo CRMA, Marcon SS. Vivência do cuidador familiar na prática do cuidado domiciliar ao doente crônico dependente. Cienc. cuid saúde. 2012;11(1):129-37.

11. Feliciani AM, Santos SSC, Valcarenghi RV. Funcionalidade e quedas em idosos institucionalizados: propostas de ações de enfermagem. Cogitare enferm. [Internet] 2011;16(4):615-21 [acesso em 10 abr 2013]. Disponível: http://ojs.c3sl.ufpr.br/ojs/index.php/ cogitare/article/viewFile/22456/17047

12. Garcia RP, Budó MLD, Oliveira SG, Schimith MD, Wünsch S, Simon BS. Cotidiano e aprendizado de cuidadores familiares de doentes crônicos. Cienc. cuid saúde.2011;10(4):690-6.

13. Marques EIW, Petuco VM, Gonçalves CBC. Motivos da não adesão ao tratamento médico prescrito entre os idosos de uma unidade de saúde da família do município de Passo Fundo - RS. RBCEH. [Internet] 2010;7(2):267-79 [acesso em 15 abr 2013]. Disponível: http://www.upf.br/seer/index.php/rbceh/article/ view/865/pdf.

14. Dourado CS, Macêdo-Costa KNF, Oliveira JS, Leadebal ODCP, Silva GRF. Adesão ao tratamento de idosos com hipertensão em uma unidade básica de saúde de João Pessoa, estado da Paraíba. Acta Scientiarum. 2011;33(1):9-17.

15. Ferreira HP, Martins LC, Brga ALF, Garcia MLB. O impacto da doença crônica no cuidador. Rev. Soc. Bras. Clin. Med. [Internet] 2012;10(4):278-84 [acesso em 10 abr 2013]. Disponível: http://files.bvs.br/ upload/S/1679-1010/2012/v10n4/a3045.pdf.

16. Silva L, Bousso RS, Galera SAF. Aplicação do Modelo Calgary para avaliação de famílias de idosos na prática clínica. Rev. bras. Enferm. [Internet] 2009;62(4):530-4 [acesso em 13 mai 2013]. Disponível: http://dx.doi. org/10.1590/S0034-71672009000400006 